\title{
A new species of cirolanid isopod, Eurydice nunomurai (Crustacea) from Izu-Ohshima Island, Sagami Sea, Pacific coast of central Japan
}

Nobuhiro Saito

\begin{abstract}
Eurydice nunomurai sp. nov. is described from Izu-Ohshima Island, Sagami Sea, Pacific coast of central Japan from a single specimen collected from the body surface of the sea whip coral on subtidal sand bottoms. Eurydice nunomurai is most similar to $E$. orientalis Hansen, 1890 but distinguished by the longer antennule, large number of antennal flagellar articles, complicated details of the serration and a large number of setae of the pleotelson posterior margin, and having a large body size.
\end{abstract}

\section{Introduction}

Use of SCUBA has made it possible to directly collect small subtidal marine animals, the biodiversity of which is still poorly understood, in subtidal habitats. Mr. Osamu Hoshino, Diving Service Chap, collected an unidentified isopod specimen from a whip coral living on the subtidal sand bottom of northeastern coast of Izu-Ohshima Island, Sagami Sea, Japan during his fieldwork, and kindly made the specimen available to me for examination. Examination of the specimen revealed that it is a new species of Eurydice Leach, 1815.

Eurydice is a large genus with 54 named species (Schotte et al., 2012), and is well-known from shallow-water marine environments world wide (Jones \& Naylor, 1967; Bruce, 1986; Brusca et al., 1995). Four species are known from Japan (Saito et al., 2000; Nunomura, 2008; Shimomura \& Nunomura, 2012): E. akiyamai Nunomura, 1981 from the estuary of Ichinomiya River, Chosei-mura, Chiba Prefecture to Nago, Okinawa Prefecture; E. longiantennata Nunomura \& Ikehara, 1985 from Tobishima, Sakata, Yamagata Prefecture; E. nipponica Bruce \& Jones, 1981 from Fukiage Beach, beaches around Kagoshima Prefecture and Shijiki Bay, Nagasaki Prefecture; and E. saikaiensis Nunomura, 2008 from Shijiki Bay, Nagasaki Prefecture. Eurydice species from Japan are occasionally found abundantly on intertidal sandy beaches and tidal sand flats (Bruce \& Jones, 1981; Nunomura, 1981). The new species, however, the first one which lives sub-tidally.

\section{Material and Methods}

The Eurydice specimen was picked directly from body surface of a sea whip coral, at $35 \mathrm{~m}$ deep of "Aki-no-hama" point, northeastern coast of Izu-Ohshima Island, on 5 March 2011, while SCUBA diving. Collected material was preserved in $70 \%$ ethanol, and transported to the laboratory. Observations were made under a binocular microscope (Olympus X-II). Measurements and drawings were made with the aid of an Olympus BHB-Tr microscope with an attached drawing tube.

Abbreviations used: BL, body length of isopod, from the tip of the cephalon to the posterior margin of the pleotelson; PS, plumose seta/e; RS, robust seta/e; SS, slender seta/e. Other measurements and terminology is essentially the same as that of cirolanid isopods used by Keable (2006). The type specimen was deposited at the Kitakyushu Museum of Natural History and Human History, Kitakyushu, Japan, with a code of KMNH IvR.

\section{Taxonomic Account}

Genus Eurydice Leach, 1815

Eurydice nunomurai sp. nov. 
(Figs. 1-4)

[New Japanese name:

Ohshima-higenaga-sunahorimushi]

Material examined.-Holotype: KMNH IvR 500,643, male (6.68 mm BL), northeastern coast of Izu-Ohshima Island (344ㄱ'14" N, 139²4'44" E), 5 March, 2011, $35 \mathrm{~m}$ deep, from body surface of a sea whip coral Cirripathes sp. (Antipatharia), coll. O. Hoshino.

Descriptions of holotype.-Body (Figs. 1, 2A) elongate, 4.4 times as long as greatest width, dorsal surface smooth, lateral margins subparallel.

Cephalon (Fig. 2C) semicircular, minute rostral process present.

Eyes (Fig. 2C) large and well developed, separated by $22 \%$ width of cephalon; each eye made up of 6 transverse rows of ommatidia in dorsal view, each row with about 6 (5-7) ommatidia.

Frontal lamina (Fig. 2D) anterior margin slightly convex.

Antennule (Fig. 2C, E) reaching beyond posterior margin of the pereonite 1 (excluding terminal stiff setae); peduncular articles 1 and 2 subequal in length; article 3 slightly shorter; flagellum composed of 4 articles, article 1 long, about 3 times as long as 2; article 3 about 1.5 times as long as 2; article 4 short, about 0.25 times as long as 3 ; article 4 with stiff setae greater in length, rather longer than combined length of flagellar articles.

Antenna (Fig. 2A, F, G) extending beyond mid-point of pleotelson; flagellum composed of 31 articles, without plicate processes.

Mandible (Fig. 3A-C), incisor with 4 rounded cusps (left), and distinct tridentate, posterior cusp weakly developed (right); molar process with 24 acute marginal spines; palp article 2 longest, 2.8 times as long as article 1, with 2 marginal PS and long 2 distal PS; article 3 with 8 long marginal RS and 2 small RS.

Maxillule (Fig. 3D, E), medial lobe with 2 large plumose RS and 1 small SS; lateral lobe with $11 \mathrm{RS}$ on distal surface.

Maxilla (Fig. 3F), lateral lobe and medial lobe with 3 and 4 SS, respectively.

Maxilliped (Fig. 3G), lateral margin of palp strongly curved, article 3 about 1.6 times wider than long, article 4 twice wider than long; endite with 2 RS.

Pereonites 1 to 3 short, pereonite 6 distinctly longer than other somites (Fig. 2A).

Sternite 7 with distally rounded penial processes (Fig. 2H), each about twice as long as basal width.

Coxae (Fig. 2B) 5 to 7 , posteroventral angles produced acute points.

Pereopods 1 to 3 robust, 7 flattened with densely marginal PS, and 4 to 6 intermediate shape and length of there. All pereopods have a morph suitable for walking.

Pereopod 1 (Fig. 4A), basis about 3 times as long as width; ischium about half length of basis, with single long RS at anterodistal angle and $1 \mathrm{RS}$ on lateral distal margin; merus about half length of ischium, posterior margin with $3 \mathrm{RS}$; carpus shorter, posterior margin with $2 \mathrm{RS}$; propodus subequal to combined lengths of ischium and carpus, with 5 RS and a long SS on palm; dactylus slightly recurved, about 0.45 times as long as propodus.

Pereopod 7 (Fig. 4B), basis about 6 times longer than width; ischium about half length of basis, posterior margin with 3 marginal RS and cluster of inferodistal RS, anterodistal angle with a cluster of RS; merus subequal in length to ischium, posterior margin with 3 clusters of marginal RS and cluster of inferodistal RS, anterior margin with 2 clusters of marginal RS and a cluster of sub-anterodistal RS; carpus slightly longer than merus, posterior margin with 4 clusters of marginal RS and cluster of inferodistal $\mathrm{RS}$, anterior margin with a cluster of subanterodistal RS; propodus subequal in length to merus, posterior margin with 3 clusters of marginal RS and cluster of inferodistal $\mathrm{RS}$, anterior margin with 4 marginal RS and anterodistal RS; dactylus about 0.3 times as long as propodus.

Pleonite 1 shorter than 2; pleonite 4 distinctly longer than other pleonites; posterolateral angles of all pleonites expanded backward with acute points (Fig. 2A, B).

Pleopod 2 (Fig. 4C, D), exopod and endopod with about 35 and 30 marginal 
PS, respectively; appendix masculina extending beyond endopod, broadest distally, distolateral margin with short apical projection; medial margin of peduncle with 3 coupling hooks and single PS, lateral margin with a distal PS.

Pleotelson (Fig. 2I, J) about 0.9 times as long as greatest width; lateral margins feebly convex; posterior margin truncate, about 0.3 times as wide as greatest width, with a pair of weakly developed lateral dentations; posterior truncated margin provided with 13 teeth, 13 PS, and two pairs of short stiff setae.

Uropod (Fig. 4E) rami lateral margins almost straight; exopod mesial margin feebly convex. Exopod about 1.7 times as long as wide, distal margin with 12 PS and 2 RS. Endopod, 15 PS on distal margin, 5 on lateral margin, and 2 RS and 2 PS on apex angle. Peduncle lateral margin with 11 PS and single RS.

Coloration.-Preserved specimen cream, with black chromatophores distributed on the dorsal surface of cephalon to anterior part of pleotelson; eye color black (Fig. 1).

Distribution.-Known only from the type locality.

Etymology.-Named in honor of Mr. Noboru Nunomura, former director of Toyama Science Museum, Toyama, Japan, for his significant contributions to the taxonomy of the Japanese isopods, including the records of Eurydice species from Japan.

Remarks.-Eurydice nunomurai sp. nov. is most similar to the widely distributed Indo-Pacific species E. orientalis Hansen, 1890. Eurydice orientalis was redescribed in detail by Bruce (1986). Both species have a truncate pleotelson posterior margin, body length of about 4 times that of width, and the antennal flagellum extends to the pleotelson. Eurydice nunomurai can be differentiated from $E$. orientalis by the length of antennule (reaching beyond posterior margin of pereonite 1 in E. nunomurai vs. reaching posterior margin of the cephalon in E. orientalis), number of antennal flagellar articles (31 articles in E. nunomurai vs. about 21 in E. orientalis), serration and setation of posterior margin of pleotelson (with 13 teeth and 13 PS in E. nunomurai vs.

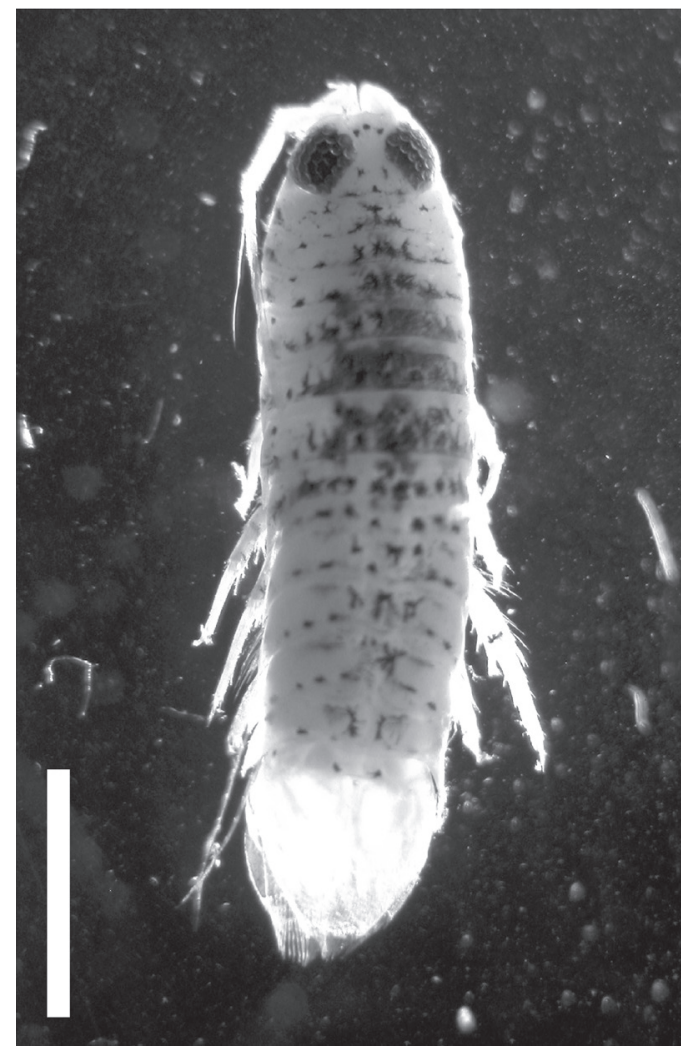

Fig. 1 Eurydice nunomurai, holotype, male $(6.68 \mathrm{~mm}$ BL), KMNH IvR 500,643, northeastern coast of IzuOhshima Island, Sagami Sea, Japan, 35 m deep. Scale bar: $2 \mathrm{~mm}$.

8 teeth and 7 PS in E. orientalis), and larger body size (6.68 $\mathrm{mm}$ BL in E. nunomurai vs. $5.0 \mathrm{~mm} \mathrm{BL}$ in maximum specimen of E. orientalis). Furthermore, the following minor characters also serve to separate $E$. nunomurai from $E$. orientalis (those of $E$. orientalis in parentheses): propodus palm of pereopod 1 with $5 \mathrm{RS}$ and a long SS (with $3 \mathrm{RS}$ ), posterior margins of merus, carpus, and propodus of pereopod 7 with 3, 4, and 3 clusters of RS, respectively, and anterior margin of propodus with 4 marginal RS (posterior margins of them with 1, 1, and 2 clusters, and anterior margin of propodus with 2 RS), and distal margins of exopod and endopod of uropod, and lateral margin of peduncle with 12, 15, and 11 marginal PS, respectively (with 7,10 , and $8 \mathrm{PS}$ ).

Two Japanese species, Eurydice 

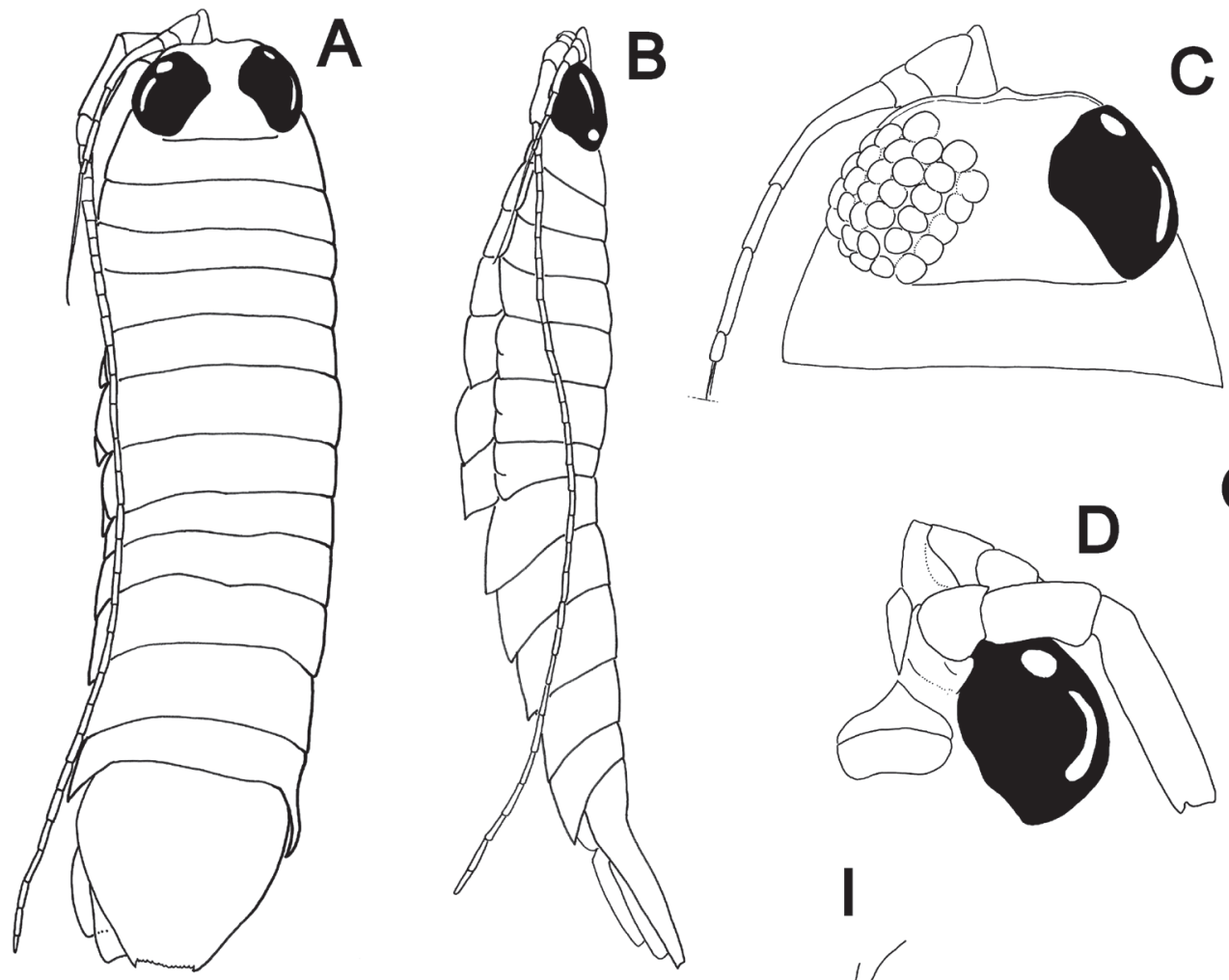

\section{$\mathrm{H}$}
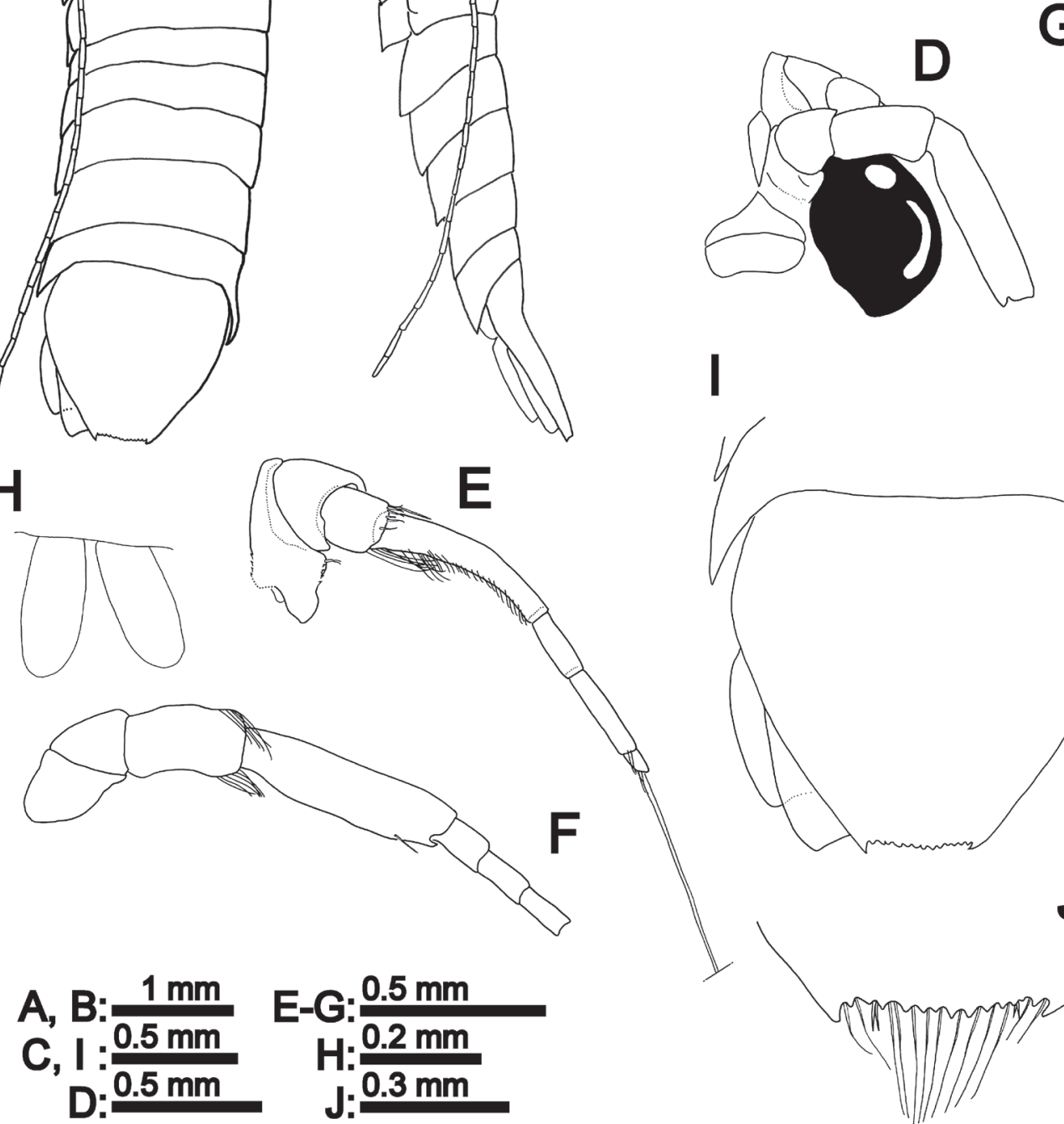

$\mathbf{G}$
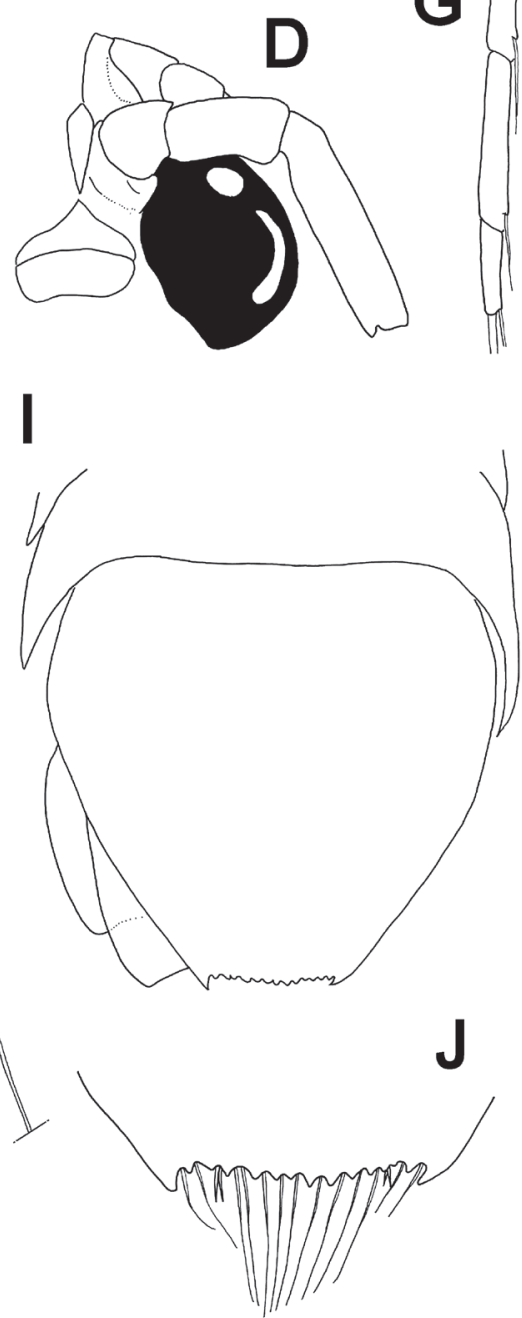

Fig. 2 Eurydice nunomurai, holotype, male (6.68 mm BL), KMNH IvR 500,643, northeastern coast of IzuOhshima Island, Sagami Sea, Japan, $35 \mathrm{~m}$ deep. Antennae dissected from right side. A, whole animal, dorsal view; B, same, lateral view; C, cephalon, dorsal view; D, frons, ventral view; E, antennule, dorsal view; F, antenna, dorsal view; G, distal articles of antennal flagellum; $\mathrm{H}$, penial process, ventral view; I, pleotelson and uropod, dorsal view; J, posterior margin of pleotelson, dorsal view. 

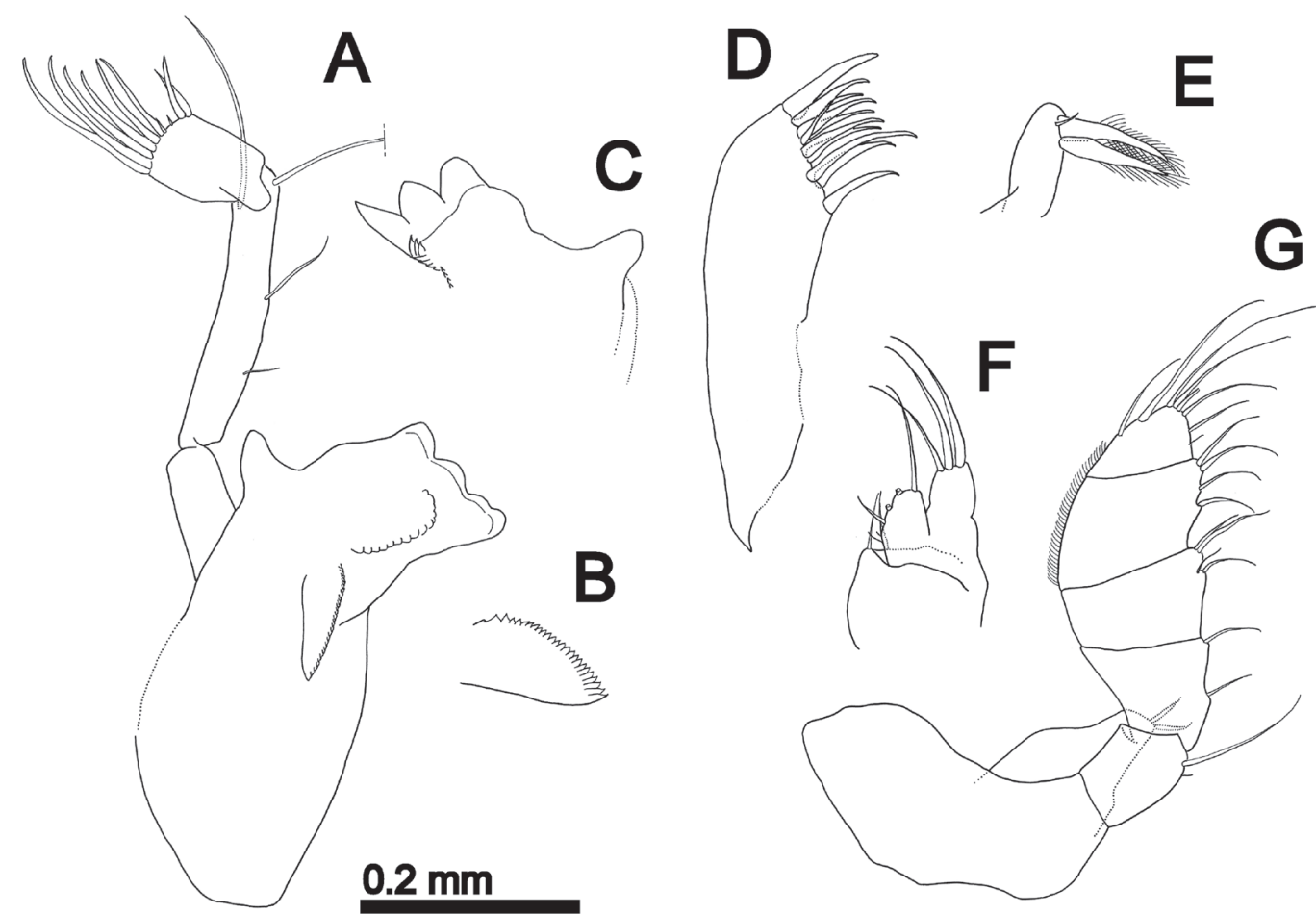

Fig. 3 Eurydice nunomurai, holotype, male (6.68 mm BL), KMNH IvR 500,643, northeastern coast of IzuOhshima Island, Sagami Sea, Japan, $35 \mathrm{~m}$ deep. A, left mandible, dorsal view; B, same, molar process; C, right mandible, incisor; D, right maxillule, lateral lobe, ventral view; E, same, medial lobe, ventral view; F, right maxilla, dorsal view; $\mathrm{G}$, right maxilliped, ventral view.

longiantennata and E. saikaiensis, also have a truncate pleotelson posterior margin and antenna extend to the pleotelson. Eurydice nunomurai is thus similar to these Japanese species. However, these species have a broader body shape (body width is about one third of the body length) and a short antennule (not reaching posterior margin of the cephalon) (Nunomura \& Ikehara, 1985; Nunomura, 2008). Furthermore, the new species can be separated from $E$. longiantennata by its larger body size (vs. 5.0 $\mathrm{mm} \mathrm{BL}$ in maximum specimen), and from E. saikaiensis by details of the pleotelson posterior margin (vs. provided with 5-6 teeth and 8 PS).

All four Eurydice species known from Japan were recorded from intertidal sand beaches, sand tidal flats, and a small creek. The new species, E. nunomurai, represents the fifth Japanese species of the genus, and first record from a subtidal habitat in Japan. Though the single specimen was taken directly from a sea whip coral, this occurrence may well be accidental as the genus and this species seems not to be symbiotic. The genus Eurydice consists of free-living species and there are no species with morphological characters indicative of a symbiotic habits such as the prehensile pereopods.

\section{Acknowledgments}

I am deeply grateful to Dr Niel L. Bruce (Museum of Tropical Queensland, Queensland Museum and School of Marine and Tropical Biology, James Cook University) for critical reading of the early manuscript and helpful suggestions; and to Dr Hiroshi Suzuki (Faculty of Fisheries, Kagoshima University), and two anonymous 


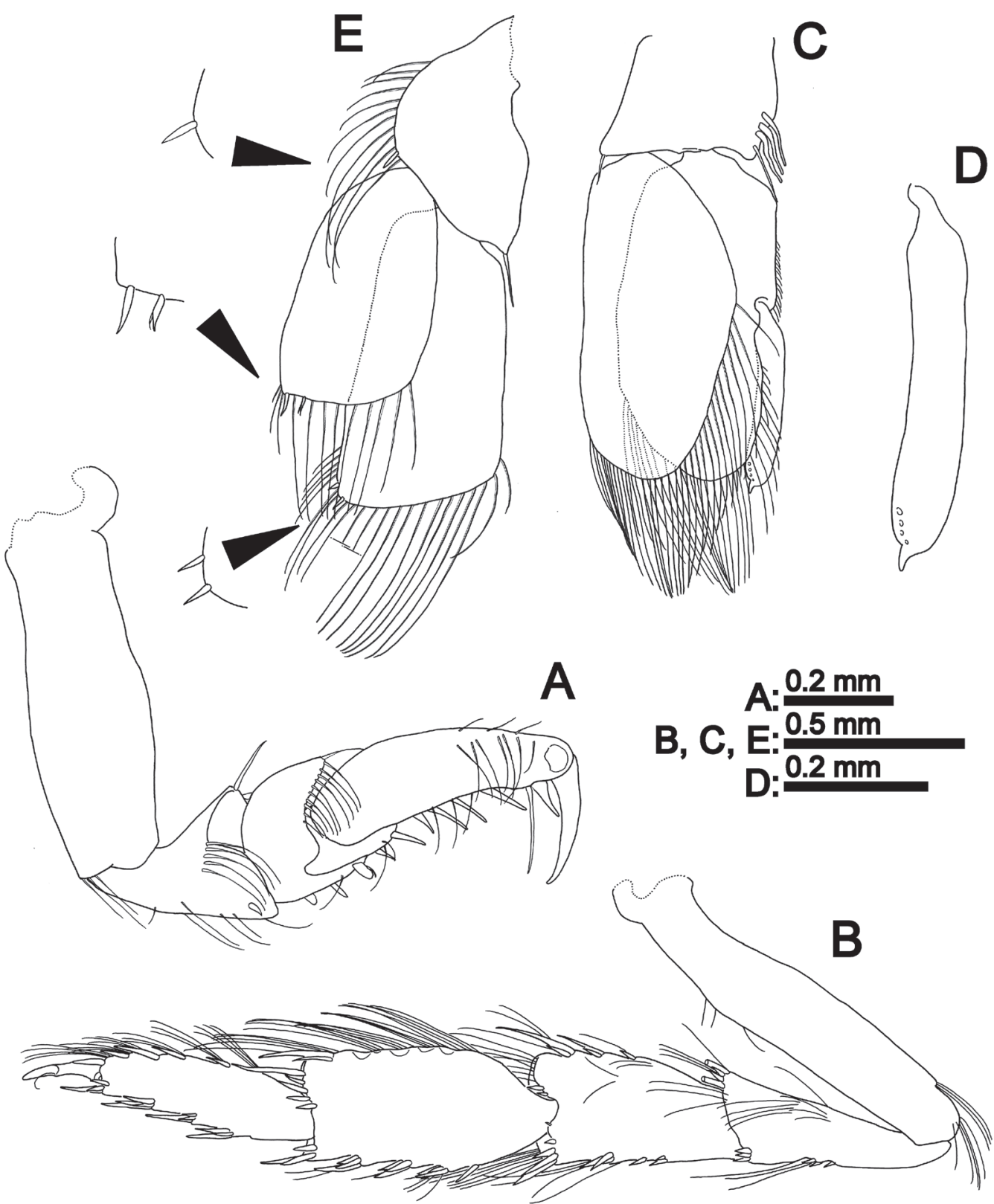

Fig. 4 Eurydice nunomurai, holotype, male (6.68 mm BL), KMNH IvR 500,643, northeastern coast of IzuOhshima Island, Sagami Sea, Japan, $35 \mathrm{~m}$ deep. All appendages dissected from right side. A, pereopod 1, lateral view; B, pereopod 7, lateral view; C, pleopod 2, ventaral view; D, appendix masculina (stylus); E, uropod, ventral view.

reviewers for their useful comments on this manuscript. I sincerely thank to $\mathrm{Mr}$. Osamu Hoshino (Diving Service Chap) for providing the material used in this study; and to Miss Hiroko Takaoka (Okinawa Churaumi Aquarium) for identifications of the sea whip coral. 


\section{Literature Cited}

Bruce, N.L., 1986. Cirolanidae (Crustacea: Isopoda) of Australia. Records of the Australian Museum, Supplement, 6: 1-239.

_ \& Jones, D.A., 1981. The systematics and ecology of some cirolanid isopods from southern Japan. Journal of Natural History, 15: 67-85.

Brusca, R.C., Wetzer, R., \& France, S.C., 1995. Cirolanidae (Crustacea: Isopoda: Flabellifera) of the tropical eastern Pacific. Proceedings of the San Diego Society of Natural History, 30: 1-96.

Jones, D.A., \& Naylor, E., 1967. The distribution of Eurydice (Crustacea: Isopoda) in British waters, including E. affinis new to Britain. Journal of the Marine Biological Association of the United Kingdom, 47: 373-382.

Keable, S.J., 2006. Taxonomic revision of Natatolana (Crustacea: Isopoda: Cirolanidae). Records of the Australian Museum, 58: 133-244.

Nunomura, N., 1981. Eurydice akiyamai sp. nov., a new isopod crustacean from an estuary in Chiba Prefecture, central Japan. Bulletin of the Toyama Science Museum, 3: 7-11.

, 2008. Marine isopod crustaceans collected from Shijiki Bay, western Japan (1) Valvifera, Cymothoida, Sphaeromatidea, Limnoriidea and Oniscidea. Bulletin of the Toyama Science Museum, 31: 13-43.

- \& Ikehara, K., 1985. Some isopod crustaceans collected in the middle coastal area of the Japan Sea. Bulletin of the Toyama Science Museum, 7: 51-69.

Saito, N., Itani, G., \& Nunomura, N., 2000. A preliminary check list of isopod crustaceans in Japan. Bulletin of the Toyama Science Museum, 23: 11-107. (in Japanese with English abstract)

Schotte, M., 2012. Eurydice Leach, 1815. In: Schotte, M., Boyko, C.B., Bruce, N.L., Poore, G.C.B., Taiti, S., \& Wilson, G.D.F. (Eds). World Marine, Freshwater and Terrestrial Isopod Crustaceans database. Accessed through: World Register of Marine Species at http://www.marinespecies.org/ aphia.php? $\mathrm{p}=$ taxdetails\&id $=118401$ on 2012 $10-18$.

Shimomura, M., \& Nunomura, N., 2012. Eurydice akiyamai. In: Japanese Association of Benthology (Ed). Threatened Animals of Japanese Tidal Flats: Red Data Book of Seashore Benthos. p.179. Tokai University Press, Hadano. (in Japanese)

Addresses: Suido-sha Co. Ltd., 8-11-11, Ikuta, Tama-ku, Kawasaki, Kanagawa 2140038, Japan.

E-mail: nsaitoh@suidosha.co.jp

RECEIVED: 3 September 2012. ACCEPTED: 5 December 2012. 